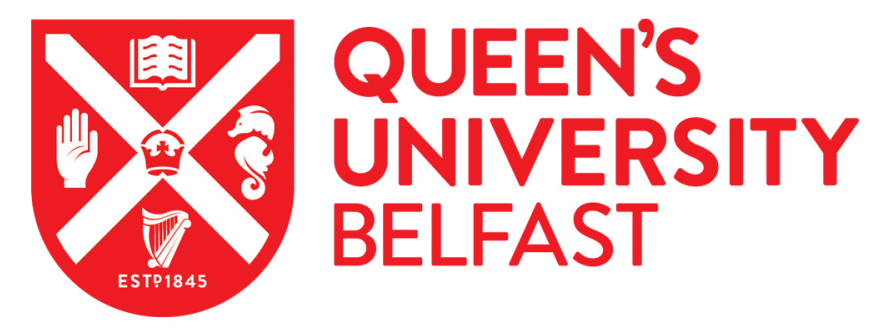

\title{
The Case Against the European Medicines Agency's Change to the Label for Radium-223 for the Treatment of Metastatic Castration- resistant Prostate Cancer
}

O'Sullivan, J. M., Heinrich, D., James, N. D., Nilsson, S., Ost, P., Parker, C. C., \& Tombal, B. (2018). The Case Against the European Medicines Agency's Change to the Label for Radium-223 for the Treatment of Metastatic Castration-resistant Prostate Cancer. European Urology. https://doi.org/10.1016/j.eururo.2018.11.003

Published in:

European Urology

Document Version:

Peer reviewed version

Queen's University Belfast - Research Portal:

Link to publication record in Queen's University Belfast Research Portal

\section{General rights}

Copyright for the publications made accessible via the Queen's University Belfast Research Portal is retained by the author(s) and / or other copyright owners and it is a condition of accessing these publications that users recognise and abide by the legal requirements associated with these rights.

Take down policy

The Research Portal is Queen's institutional repository that provides access to Queen's research output. Every effort has been made to ensure that content in the Research Portal does not infringe any person's rights, or applicable UK laws. If you discover content in the

Research Portal that you believe breaches copyright or violates any law, please contact openaccess@qub.ac.uk. 
Urology

Elsevier Editorial System(tm) for European

Manuscript Draft

Manuscript Number: EURUROL-D-18-01436

Title: The Case Against the European Medicines Agency's Change to the Label for Radium-223 for the Treatment of Metastatic Castration-resistant Prostate Cancer

Article Type: Letter to the Editor

Section/Category: Prostate Cancer (PRO)

Keywords: Radium-223

Europen Medicines Agency

ERA-223

Abiraterone

Corresponding Author: Professor Joe O'Sullivan, MD FRCPI FFRRCSI FRCR

Corresponding Author's Institution: Queen's University Belfast

First Author: Joe O'Sullivan, MD FRCPI FFRRCSI FRCR

Order of Authors: Joe O'Sullivan, MD FRCPI FFRRCSI FRCR; Daniel Heinrich, MD; Nicholas D James, MD; Sten Nilsson, MD; Piet Ost, MD; Christopher C Parker, MD; Bertrand Tombal, MD 
All authors contributed to the concept, composition, editing, and final approval of the article.

Conflicts of Interest;

Joe O'Sullivan: Advisory Board, Speakers Bureau: Astellas, Bayer, Janssen, Sanofi. Research funding (Institute) Bayer

Daniel Heinrich: Honoraria and consultancy: Astellas, Bayer, Janssen-Cilaq, Roche

Nick James: Consultancy. Bayer, Astellas, Janssen, Merck, AstraZeneca, Clovis, Endocyte, Sanofi, Roche

Travel Janssen, Sanofi,

Speakers fees Janssen, Bayer, Ipsen

Sten Nilsson: Participation in advisory board meetings for Bayer Healthcare, Astellas, Janssen, Amgen and Sanofi-Genzyme, respectively. Participation as lecturer in meetings sponsored by Bayer, Astellas, Janssen, Sanofi-Genzyme, Pfizer and Astra-Zeneca, respectively.

Piet Ost: Institutional funding: speaker and consultancy fees from Bayer, Astellas, Janssen and Ferring.

Chris Parker: Research funding and advisory boards for Bayer. Advisory boards for AAA and Speaker fees for Jansen

Bertrand Tombal: paid advisor for Amgen Bayer, Astellas, Ferring, Myovant 


\section{The Case Against the European Medicines Agency's Change to the Label for Radium- 223 for the Treatment of Metastatic Castration-resistant Prostate Cancer}

We write regarding a recent label change recommended by the Pharmacovigilance Risk Assessment Committee (PRAC) and implemented by the European Medicines Agency (EMA) for the bone-targeted agent radium-223 (Xofigo) [1]. The EMA has concluded its review of the cancer medicine and has recommended restricting its use to patients who have had two previous treatments for metastatic castration-resistant prostate cancer (mCRPC) or who cannot receive other treatments. Depending on how these recommendations are interpreted, they might effectively restrict the use of this agent to the terminal phase of the illness. We believe that these restrictions are not justified on the basis of the available evidence and could result in fewer patients benefiting from this drug. Radium-223 (Xofigo) has been licensed since 2013 for the treatment of patients with symptomatic mCRPC involving bone, with no visceral metastases. This licence was based on the improvement in overall survival (OS) demonstrated (hazard ratio [HR] 0.7) in the ALSYMPCA registration trial, which compared six cycles of radium-223 plus best standard of care to placebo plus best standard of care [2]. The trial also demonstrated a significant reduction in the risk of symptomatic skeletal events (HR 0.6). The benefits were similar whether or not men had received palliative chemotherapy with docetaxel, the only lifeprolonging therapy approved for CRPC at the time of the trial. Further evidence of the benefit and safety of radium-223 has emerged over the past number of years [3,4].

The PRAC review of radium-223 was carried out in response to data from an unplanned interim analysis of a randomised trial comparing radium-223 plus abiraterone acetate and prednisolone versus placebo plus abiraterone acetate and prednisolone (ERA 223) in men with progressive mCRPC involving bone and no previous chemotherapy or abiraterone or enzalutamide. The agency's recommendations are based on an assessment of ERA 223 trial data that showed that for patients receiving radium-223 in combination with abiraterone/prednisolone, there was a higher incidence of bone fractures $(28.6 \%$ vs $11.4 \%)$ and a possible reduction in OS (30.7 vs $33.3 \mathrm{mo}$; HR 1.195, 95\% confidence interval [CI] $0.950-1.505 ; p=0.13$ ).

There was clearly a higher risk of fractures associated with use of radium-223 in ERA 223. This risk was reduced, but not abolished, when bone health agents (bisphosphonates or denosumab) were used. Routine imaging was not performed in ALSYMPCA and so it is not possible to know whether radium-223 also caused excessive asymptomatic fractures in that trial. Even if there were a higher risk of undetected asymptomatic fractures, ALSYMPCA does provide direct evidence of the lack of effect of radium-223 on clinically relevant fractures in the first- or second-line CRPC setting in the absence of exposure to abiraterone. For agents such as radium-223 and abiraterone, which have both been shown to improve OS and quality of life, the associated risk of fractures is part of an acceptable risk-benefit profile. Indeed, of all the life-prolonging therapies for mCRPC, radium-223 has the most favourable toxicity profile, even accepting a risk of fracture. This led to the highest possible score on the ESMO Clinical Benefit Scale for radium-223, higher than for the other four life-prolonging therapies [5].

The PRAC has essentially suggested that the results of this combination trial should be extrapolated to patients treated under the previous label (symptomatic mCRPC involving bone and no evidence of visceral metastases). Combination of radium-223 with an effective therapy such as abiraterone is a very different clinical scenario to the standard use of radium223 as monotherapy (along with androgen deprivation and supportive therapies). 
We strongly disagree with the PRAC interpretation of the ALSYMPCA data, in which they use the OS forest plot from the trial to claim that because the CI for the HR for OS crossed unity for patients with fewer than six bone metastases (HR 0.95, 95\% CI 0.46-1.95) and for alkaline phosphatase <220 U/l (HR 0.82, 95\% CI 0.64-1.07), such patients would not benefit in terms of OS and should not be offered radium-223.

The subgroup analyses in the forest plot tested for heterogeneity of effect and should not be used to test for treatment benefit in a particular subgroup. This topic is discussed in some depth in a recent article by one of the authors of this letter [6].

We agree that radium-223 should not be used in combination with abiraterone acetate and prednisolone/prednisone. However, we disagree with the recommendation that it should be reserved for third or later lines of therapy in MCRPC. We believe that the OS benefit from radium-223 plus best standard of care should not be in doubt as a result of the new data from ERA 223. Restricting the use of radium-223 to the third line in mCRPC will mean that many patients who could benefit will be denied access. In particular, patients with symptomatic bone metastases who are too frail to receive docetaxel or cabazitaxel or indeed who do not want cytotoxic chemotherapy may be denied access. For these patients who only have abiraterone or enzalutamide available as survival-prolonging options, the recommendation can be read as encouraging sequential use of abiraterone after enzalutamide, or vice versa, before an indication for radium-223. However, there is plenty of evidence that these sequences do not work, so this strategy would expose patients to useless expensive drugs [7]. For patients fit enough for docetaxel and/or cabazitaxel, the increasing likelihood of visceral metastases with increasing mCRPC duration [8] means that as these patients move on to third-line therapy, they are much less likely to be suitable for radium-223. If they do start radium-223, they are more likely to experience early visceral disease progression. Of note, other drugs agencies including the US Food and Drug Administration, the Canadian Agency for Drugs and Technologies in Health, and the Japanese Pharmaceuticals and Medical Devices Agency have assessed the same data as the EMA and have decided on no change to the label for radium-223.

Conflicts of interest: Joe O'Sullivan has received advisory board and speaker bureau fees from Astellas, Bayer, Janssen, and Sanofi; and institutional research funding from Bayer. Daniel Heinrich has received honoraria and consultancy fees from Astellas, Bayer, JanssenCilaq, and Roche. Nicholas D. James has received consultancy fees from Bayer, Astellas, Janssen, Merck, AstraZeneca, Clovis, Endocyte, Sanofi, and Roche; travel expenses from Janssen and Sanofi; and speaker fees from Janssen, Bayer, and Ipsen. Sten Nilsson has participated in advisory board meetings for Bayer Healthcare, Astellas, Janssen, Amgen, and Sanofi-Genzyme and as a lecturer in meetings sponsored by Bayer, Astellas, Janssen, SanofiGenzyme, Pfizer, and AstraZeneca. Piet Ost has received institutional funding and speaker and consultancy fees from Bayer, Astellas, Janssen, and Ferring. Christopher C. Parker has received research funding and advisory board fees from Bayer, advisory board fees from AAA, and speaker fees from Jansen. Bertrand Tomball has been paid as an advisor for Amgen Bayer, Astellas, Ferring, and Myovant.

\section{References}

1 European Medicines Agency. EMA restricts use of prostate cancer medicine Xofigo. www.ema.europa.eu/medicines/human/referrals/xofigo

2 Parker C, Nilsson S, Heinrich D, et al. Alpha emitter radium-223 and survival in metastatic prostate cancer. N Engl J Med 2013;369:213-23. 
3 Parker CC, Pascoe S, Chodacki A, et al. A randomized, double-blind, dose-finding, multicenter, phase 2 study of radium chloride ( $\mathrm{Ra} 223$ ) in patients with bone metastases and castration-resistant prostate cancer. Eur Urol 2013;63:189-97.

4 Parker C, Finkelstein SE, Michalski JM, et al. Efficacy and safety of radium-223 dichloride in symptomatic castration-resistant prostate cancer patients with or without baseline opioid use from the phase 3 ALSYMPCA trial. Eur Urol 2016;70:875-83.

5 Cherny NI, Sullivan R, Dafni U, et al. A standardised, generic, validated approach to stratify the magnitude of clinical benefit that can be anticipated from anti-cancer therapies: the European Society for Medical Oncology magnitude of clinical benefit scale (ESMO-MCBS). Ann Oncol 2017;28:2901-5.

6 Spears MR, James ND, Sydes MR. "Thursday's child has far to go"-interpreting subgroups and the STAMPEDE trial. Ann Oncol 2017;28:2327-30.

7 Annala M, Vandekerkhove G, Khalaf D, et al. Circulating tumor DNA genomics correlate with resistance to abiraterone and enzalutamide in prostate cancer. Cancer Discov 2018;8:444-57.

8 Pezaro C, Omlin A, Lorente D, et al. Visceral disease in castration-resistant prostate cancer. Eur Urol 2014;65:270-3.

Joe O’Sullivan $^{\mathrm{a}, *}$, Daniel Heinrich ${ }^{\mathrm{b}}$, Nicholas D. James ${ }^{\mathrm{c}}$, Sten Nilsson ${ }^{\mathrm{d}}$, Piet Ost ${ }^{\mathrm{e}}$, Christopher C. Parker ${ }^{\mathrm{f}}$, Bertrand Tombal ${ }^{\mathrm{g}}$

${ }^{a}$ Centre for Cancer Research and Cell Biology, Queen's University, Belfast City Hospital, Belfast, UK

${ }^{\mathrm{b}}$ Akershus University Hospital, Lørenskog, Norway ${ }^{\mathrm{c}}$ University Hospitals Birmingham NHS Foundation Trust, Birmingham, UK

${ }^{\mathrm{d}}$ Karolinska Hospital, Stockholm, Sweden ${ }^{\mathrm{e}}$ Ghent University, Ghent, Belgium

${ }^{\mathrm{f}}$ Institute of Cancer Research, Sutton, UK ${ }^{\mathrm{g}}$ Université Catholique de Louvain, Louvain, Belgium

* Corresponding author. Centre for Cancer Research and Cell Biology, Queen's University, Belfast City Hospital, Belfast BT9 7AB, UK. Tel. +44 2895048549. E-mail address: joe.osullivan@qub.ac.uk (J. O’Sullivan). 